\title{
Coordinated Microanalysis of Phosphates in High-Titanium Lunar Basalts
}

\author{
J. J. Barnes ${ }^{1}$, M. S. Thompson ${ }^{1}$, F. M. McCubbin ${ }^{1}$, J. Y. Howe ${ }^{2}$, Z. Rahman ${ }^{3}$, S. Messenger ${ }^{1}$, and T.
} Zega $^{4}$.

1. ARES, NASA, Johnson Space Center (JSC), Houston, TX.

2. Hitachi High-Technologies America Inc.

3. JETS JACOBS, NASA, JSC, Houston, TX.

4. Lunar and Planetary Laboratory (LPL), University of Arizona, Tucson, AZ.

Laboratory studies of lunar apatite $\left[\mathrm{Ca} 5\left(\mathrm{PO}_{4}\right)_{3}(\mathrm{~F}, \mathrm{Cl}, \mathrm{OH})\right]$ have been important for determining the volatile inventory of the interior and the roles volatiles played during the magmatic evolution of the Moon [1]. It has been suggested that high-Ti mare basalts sample volatiles from a distinct reservoir in the lunar mantle [2]. However, there is still debate surrounding the crystallization and post-crystallization history of apatite in those basalts [3-5]. This information is required before we can use apatite to characterize the abundance or isotopic composition of volatiles in melts or magmatic source regions. Our goal is to investigate the mineral chemistry, crystal structure, and volatile inventory of phosphates in high-Ti basalts from Apollo 11 , which will allow us to determine the crystallization history of apatite in these rocks and identify any potential secondary processes that have changed the volatile composition that apatite acquired from the melt.

Two distinct geochemical varieties of Apollo 11 high-Ti basalts (10024 and 10029) were selected for general mineralogical, chemical, and textural study to investigate the high-Ti basalt volatile reservoir(s). 10024 is a high-K basalt with $\sim 0.33$ wt. $\% \mathrm{~K}_{2} \mathrm{O}, \sim 31 \mathrm{ppm} \mathrm{La}$, and $\sim 5 \mathrm{ppm}$ Th [6]. 10029 is a low-K basalt with 0.03 to 0.08 wt. $\% \mathrm{~K}_{2} \mathrm{O}$ and relatively high rare earth element (REE) abundances ( $22 \mathrm{ppm}$ La and $\sim 1.8 \mathrm{ppm}$ Th [6]) compared to other low-K basalts [6]. A zoned apatite crystal from 10029 (Phosphate\#1, Figure $1 \mathrm{~A})$ and an apatite-merrillite $\left[(\mathrm{Mg}, \mathrm{Fe})_{2} \mathrm{REE}_{2} \mathrm{Ca}_{16}\left(\mathrm{PO}_{4}\right)_{14}\right]$ intergrowth with vermicular features (symplectite) in 10024 (Phosphate\#2, Figure 1B) were chosen for further study by coordinated transmission electron microscopy (TEM) and nanoscale secondary ion mass spectrometry (NanoSIMS). These target crystals were extracted with focused ion beam (FIB) milling using the FEI Quanta 3D dual FEG-SEM at JSC. FIB sections were analyzed using the aberration-corrected Hitachi HF5000 TEM at LPL, equipped with twin large-area EDS detectors with $~ 2.0$ SR solid angle. We were able to collect highresolution EDS X-ray maps for major elements and REEs in <30 minutes. Selected-area electrondiffraction (SAED) patterns were acquired for phase identification and determination of crystal structure. NanoSIMS analyses are underway.

The high-resolution EDS data from the TEM reveals that Y and REEs (Figure 1C) as well as Si and Cl increase from core-to-rim of Phosphate\#1 whilst there is a corresponding decrease in both $\mathrm{Ca}$ and $\mathrm{P}$ from core-to-rim. We oriented the core of the crystal to the zone axis and evaluated the relative orientation of the outer zones. We found that the crystallographic orientation is uniform from core-to-rim, even in the outermost rim (brightest zone, Figure 1A) indicating that Phosphate\#1 is a single crystal that grew continuously rather than the zones representing later overgrowths. Overall, the results suggest that this crystal was formed by fractional crystallization, most likely via a coupled substitution: $\mathrm{P}^{5+}+\mathrm{Ca}^{2+} \leftarrow \rightarrow$ $\mathrm{Si}^{4+}+\mathrm{REE}^{3+}$ [7]. As predicted by the apatite fractional crystallization model [4], the $\mathrm{Cl}$ abundance of the apatite is highest in the rim of the grain while $\mathrm{F}$ is lowest in the rim. This crystal will be analyzed by NanoSIMS to more accurately determine the distribution of volatiles and REEs from core to rim. 
From TEM EDS analyses of Phosphate\#2 the mineral forming a symplectite assemblage with apatite (Figure 1B) is likely monazite $\left[(\mathrm{Ce}, \mathrm{Nd}, \mathrm{La}) \mathrm{PO}_{4}\right]$ or a monazite-like phase owing to the presence of yttrium and heavy REEs. Monazite is indicated by SAED but we are in the process of acquiring nano-diffraction data to confirm this identification. Lunar monazite has been reported previously [e.g., 8-9], however, to our knowledge, texturally similar inclusions to those we identified have yet to be reported. Of the samples we studied (as part of our broader lunar volatiles campaign), symplectic monazite has only been found in the incompatible trace element-enriched high-K, high-Ti basalts from Apollo 11. These features may represent exsolution of a monazite/monazite-like phase from apatite, based on the high-temperatures and high REE abundances in the melt at the time of basalt crystallization. We are further investigating the physicochemical implications of apatite-monazite symplectite formation on the Moon.

In summary, we found direct evidence for fractional crystallization of lunar apatite and did not observe any evidence for metasomatism having taken place. Therefore, the volatile inventories of apatite in these two basalts, and texturally similar basalts, likely record the volatile composition of the melt at the time of apatite crystallization [10].

\section{References:}

[1] F. M. McCubbin et al, Amer. Mineral., 100 (2015), p.1668-1707.

[2] J. J. Barnes et al, Proc. LPSC XLVIII (2017), p.1727.

[3] R. Tartèse et al, GCA 122 (2013), p.58-74.

[4] J. W. Boyce et al, Science 344 (2014), p.400-402.

[5] B. A. Konecke, A. Fiege, A. C. Simon, and F. Holtz, Geology 45 (2017), p.739-742.

[6] C. Meyer, Lunar Sample Compendium (2012).

[7] J. G. Rønsbo, Amer. Mineral., 74 (1989), p.896-901.

[8] J. F. Lovering, D. A. Wark, A. J. W. Gleadow and R. Britten, EPSL 21 (1974), p.164-168.

[9] B. L. Jolliff, Proc. LPSC XXIV (1994), p. 724.

[10] This work is supported by a NASA postdoctoral fellowship (Barnes) NASA's LASER program grant \#NNX13AK32G (McCubbin). We thank CAPTEM for allocating Apollo samples to this project. We gratefully acknowledge NASA (grants \#NNX12AL47G and \#NNX15AJ22G) and NSF (grants \#1531243 and \#0619599) for funding of instrumentation in the Kuiper Materials Imaging and Characterization Facility.
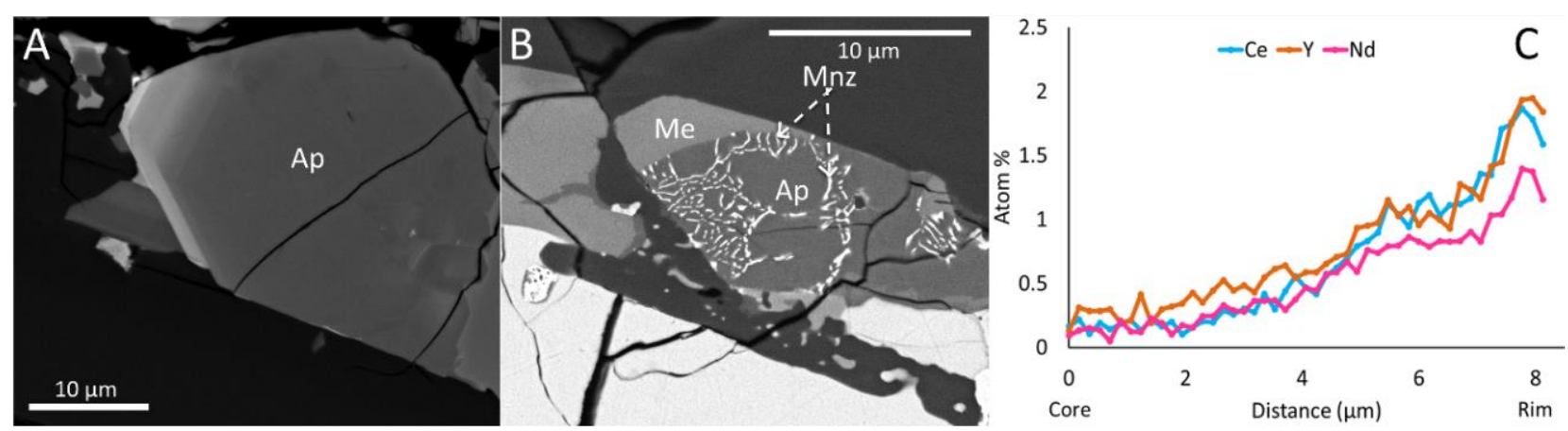

Figure 1. Back-scattered electron images of the phosphates studied by TEM A) zoned apatite (Ap) from 10029, B) symplectite assemblage of Ap, merrillite (Me), and monazite (Mnz) in 10024, and C) core-to-rim TEM EDS chemical composition profiles of Phosphate\#1. 